\title{
Process evaluation of implementation fidelity of the integrated chronic disease management model in two districts, South Africa
}

Limakatso Lebina ${ }^{1,2^{*}}$, Olufunke Alaba ${ }^{3}$, Ashley Ringane ${ }^{1}$, Khuthadzo Hlongwane ${ }^{1}$, Pogiso Pule ${ }^{1}$, Tolu Oni ${ }^{2,4}$ and Mary Kawonga ${ }^{5}$

\begin{abstract}
Background: The Integrated Chronic Disease Management (ICDM) model has been implemented in South Africa to enhance quality of clinical services in Primary Healthcare (PHC) clinics in a context of a high prevalence of chronic conditions and multi-morbidity. This study aimed to assess the implementation fidelity (adherence to guidelines) of the ICDM model.
\end{abstract}

Methods: A cross-sectional study in 16 PHC clinics in two health districts in South Africa: Dr. Kenneth Kaunda (DKK) and West Rand (WR). A fidelity assessment tool with 89 activities and maximum score of 158 was developed from the four interrelated ICDM model components: facility re-organization, clinical supportive management, assisted self-management and strengthening of support systems. Value stream mapping of patient flow was conducted to analyse waiting time and identify operational inefficiencies. ICDM items were scored based on structured observations, facility document reviews and structured questionnaires completed by healthcare workers. Fidelity scores were summarized using medians and proportions and compared by facilities and districts using Chi-Square and Kruskal Wallis test.

Results: The monthly patient headcount over a six-month period in these 16 PHC clinics was a median of 2430 (IQR: 1685-2942) individuals over 20 years. The DKK district had more newly diagnosed TB patients per month [median 5.5 (IQR: 4.00-9.33) vs 2.0 (IQR: 1.67-2.92)], and fewer medical officers per clinic [median 1 (IQR: 1-1) vs 3.5 (IQR:2-4.5)] compared to WR district. The median fidelity scores in both districts for facility re-organization, clinical supportive management, assisted self-management and strengthening of support systems were $78 \%$ [29/37, IQR: 27-31)]; 77\% [30/39 (IQR: 27-34)]; 77\% [30/39 (IQR: 28-34)]; and 80\% [35/44 (IQR: 30-37)], respectively. The overall median implementation fidelity of the ICDM model was 79\% (125/158, IQR, 117-132); WR was 80\% (126/158, IQR, 123-132) while DKK was 74\% (117/158, IQR, 106-130), $p=0.1409$. The lowest clinic fidelity score was 66\% (104/158), while the highest was $86 \%(136 / 158)$. A patient flow analysis showed long ( $2-5$ h) waiting times and one stream of care for acute and chronic services.

Conclusion: There was some variability of scores on components of the ICDM model by PHC clinics. More research is needed on contextual adaptations of the model.

Keywords: Intervention adherence, ICDM model, Chronic care model, Implementation research, Value stream mapping

\footnotetext{
* Correspondence: lebinal@phru.co.za

${ }^{1}$ Perinatal HIV Research Unit (PHRU), SA MRC Soweto Matlosana

Collaborating Centre for HIV/AIDS and TB, Faculty of Health Sciences,

University of the Witwatersrand, Johannesburg, South Africa

${ }^{2}$ Division of Public Health Medicine, School of Public Health and Family

Medicine, University of Cape Town, Cape Town, South Africa

Full list of author information is available at the end of the article
}

(c) The Author(s). 2019 Open Access This article is distributed under the terms of the Creative Commons Attribution 4.0 International License (http://creativecommons.org/licenses/by/4.0/), which permits unrestricted use, distribution, and reproduction in any medium, provided you give appropriate credit to the original author(s) and the source, provide a link to the Creative Commons license, and indicate if changes were made. The Creative Commons Public Domain Dedication waiver (http://creativecommons.org/publicdomain/zero/1.0/) applies to the data made available in this article, unless otherwise stated. 


\section{Background}

Delivering integrated, patient-centred health services is a global public health priority [1]. One of the recommended strategies of the World Health Organization (WHO) to improve the delivery of integrated chronic care at primary care level is the Innovative Care for Chronic Conditions framework, which reduces fragmentation of care and supports partnerships with communities and families in disease management [2]. Based on this recommendation, many countries have implemented various models of integrated care for chronic conditions, including communitybased programmes with repeat collection of medication [3-5], nurse-managed programmes [5] and integrated mental health, diabetes and cardiovascular disease services [6]. In South Africa, the Integrated Chronic Disease Management (ICDM) model was adopted as a national programme for implementation at primary care level. The goal was to reduce fragmentation of care for people living with multiple chronic conditions, to improve efficiency and the satisfaction experience of healthcare workers and patients, and ultimately clinical outcomes [7]. This was also in response to the high quadruple burden of communicable, non-communicable, injury-related and perinatal diseases and associated multi-morbidity [8-11].

\section{The ICDM model}

The ICDM model is an approach to managed care that was developed based on the principles of the chronic care management model and the Innovative Care for Chronic conditions (ICCC) [2, 12]. A pilot phase of introducing the model in PHC clinics in South Africa started in 2011 [13]. The ICDM model provides technical interventions on how to strengthen health services for patients with chronic multi-morbidity through four interrelated components of action points. These components are as follows [7]:

- Facility re-organization to strengthen administration, infrastructure, human resource and dispensing of medication for operational efficiency;

- Clinical supportive management to enhance quality care using appropriate clinical guidelines with the assistance of the district clinical specialist team;

- Assisted self-management which entails empowering patients to take responsibility for their disease control and providing community-based point-ofcare testing and medication delivery by outreach teams; and

- Strengthening of support systems through partnerships with external structures, equipment, medicine and information management [7].

The ICDM model's priority standards are designed to align with the national core quality standards for $\mathrm{PHC}$ facilities, which include patient safety and infection control, improving values and attitudes of staff, improving waiting times and cleanliness, and ensuring availability of medicines and supplies [7]. The chronic diseases that are included in the ICDM model are non-communicable [mental health, epilepsy, asthma, hypertension, diabetes and chronic obstructive pulmonary disease (COPD)] and communicable diseases [HIV/AIDS and all forms of tuberculosis (TB)] [7]. Continuum of care is supported at facility, community and population level under the ICDM model [7].

The ICDM programme is an integral part of the PHC reengineering initiative [7], a major health system strengthening focus of which is the South African Department of Health's (DOH) efforts to strengthen their focus as it works towards achieving universal health coverage through a national health insurance plan [14-16]. This includes the ongoing ideal clinic realisation and maintenance (ICRM) programme that was commenced in 2013 [17]. The ICRM programme is a comprehensive systematic process of improving and maintaining PHC facilities' conformance to national standards on functional infrastructure and equipment, adequate personnel and medicines and supplies, good administrative processes and the use of applicable protocols and guidelines in diseases management [17]. The Integrated Clinical Services Manual (ICSM) was included in the ICRM programme to extend the application of the ICDM model components to acute, preventative and health support services as part of scaling-out [18]. Chronic diseases has been included as one of the streams of the ICSM [18]. A scaling-out of interventions (delivery in new systems/populations) or scaling-up within the same context implies that the original core elements are maintained to achieve expected outcomes [19]. However, contextual adaptations to the intervention while maintaining the core components in the scale-up and scale-out could also be regarded as propensity towards adherence [20]. Studies on the effectiveness of the ICDM model have shown its contribution to improvements in patients records management through administrative re-organization and improved clinical outcomes through clinical supportive management and assisted self-management for patients on antiretroviral medication [21, 22]. However, some of the expected benefits have not been achieved [23]. It is not clear whether this limited success indicates low effectiveness of the model or low implementation effectiveness.

The field of implementation science provides approaches for assessing implementation effectiveness [24, 25]. Implementation research assists in assessing whether the failure of an intervention to achieve its outcomes is as a result of intervention failure or implementation failure [24]. Implementation effectiveness or success can be determined by measuring implementation outcomes such 
as fidelity (the extent to which the ICDM model is implemented according to the planned prescribed activities) or other outcomes (including acceptability, adoption, reach, implementation costs and sustainability) that serve as intermediate indicators of intervention or innovation effectiveness [24, 26]. Fidelity of implementation - the extent to which delivery of an intervention or programme follows the original design - affects how well the intervention or programme achieves its expected outcomes $[27,28]$. Fidelity is also referred to as adherence to intervention guidelines [28]. As conceptualised by Carroll, the degree of adherence to the implementation plan or guidelines can be influenced by moderating factors like intervention complexity, strategies to support implementation, quality of delivery and participant responsiveness [28]. Planned or accidental adaptations in implementing interventions could also be viewed as strategies to enhance feasibility, reach, adoption, and acceptability of the intervention in a specific context $[29,30]$. However, adaptation could affect the fidelity and effectiveness of the intervention, especially if its core components have been removed or modified $[19,29,30]$. Therefore, there is a constant tension between fidelity and modifying interventions to be suitable for a particular context $[29,30]$. Since the ICDM model development was an adaptation of the ICCC for the South African health context [7], it would be expected that it would be implemented with minimal adaptations and high fidelity, but this has not been evaluated. Moreover, in a decentralized health system, like South Africa, sub-national levels (provinces and districts) may further adapt innovations for a better fit with their contexts [31]. However, whether and the extent to which such further adaptations have been done has not been evaluated.

In South Africa, following the pilot and scale-up of the ICDM model [32], there is a dearth of studies on the implementation fidelity of the ICDM model. This study assesses the implementation fidelity, which we define as adherence to the prescribed activities in the ICDM model as outlined in the implementation manual [7]. This study aims to evaluate the implementation fidelity of the ICDM model in two health districts in South Africa. The lessons learned on assessing fidelity of the ICDM model could be applied to the ICSM in the context of the ICRM programme. Assessing the ICDM model implementation fidelity will identify areas that need strengthening to promote the sustainability of the model's principles.

\section{Methods}

This was a cross-sectional study conducted between August 2018 to March 2019 in two health districts in South Africa. It is a sub-study of a larger study that assessed the fidelity of implementation, its contextual determinants and the costs of implementing the ICDM model [33].

\section{Study setting}

The South African health system is divided into 52 health districts across nine provinces, with health service administration decentralized to district health management teams [16, 34]. Most of the population is uninsured $(82 \%)$ and utilizes state facilities where most healthcare services are free or provided at a low user fee $[14,35,36]$. Nurse-driven primary care services in each district are provided at PHC clinics (8-h service) and community health centres (24-h service) that provide preventative and curative (acute and chronic) services. As part of the PHC re-engineering framework, each clinic should have ward-based outreach teams (WBOTs) of community healthcare workers $(\mathrm{CHCW})$ providing homeand community-based health services [17, 37]. Each health districts is required to have a District Clinical Specialist team (DSCT) consisting of specialist nurses and doctors that provide supportive supervision and clinical governance $[17,38]$. The ICDM model activities for the WBOTs and $\mathrm{CHCW}$ include adherence support, home-based care and community campaigns, while the DCST activities include mentoring, training and clinical audits $[7,18]$.

The ICDM model was piloted from 2011 in three health districts: West Rand (WR) in Gauteng, Bushbuckridge in Mpumalanga and Dr. Kenneth Kaunda (DKK) in North West [13]. Two (WR and DKK) of these health districts were included in this study. Both the WR and DKK health districts are divided into four sub-districts and have similar population sizes, 810,000 in WR and 715,000 in DKK [39]. There are four community health centres and 39 PHC clinics in WR, while DKK has nine community health centres and $27 \mathrm{PHC}$ clinics. Although the literacy rate is slightly higher in WR (98\% vs $90 \%)$, employment is higher (75\% vs $71 \%)$ in DKK [40]. In WR, the proportion of informal housing is $19 \%$, while in DKK it is $21 \%$ [40]. In Gauteng, more people (34\%) are considered to be obese or overweight compared to the $16 \%$ in North West [41]. There is also a high prevalence of hypertension (36 and 39\%) [39] and diabetes (8 and 13\%) [41] in WR and DKK, in that order. TB incidence is higher (696 vs 440 per 100,000) in DKK [39], and the human immune deficiency syndrome (HIV) prevalence in antenatal women is $28 \%$ in both provinces [42].

\section{Study sample}

There were eight ICDM model pilot clinics in DKK and 12 in WR that were considered for inclusion in this study. The ICDM model pilot clinics were selected for inclusion based on the number of patients that receive health services per month (headcounts) to ensure that clinics had comparable patient case-loads. Four clinics from the WR district were excluded as the patient load in those clinics was much higher compared to DKK clinics. A total of 16 (eight per district) that were selected 
were functional without major interruptions (closures, renovations) in the 2 years preceding participation in the study. Six to eight healthcare workers (administrators, nurses, pharmacists assistants, facility managers, ICDM champions) were interviewed (for completion of the structured questionnaire) or observed in each facility.

\section{Data collection and measurement}

The study aimed to collect data on the characteristics of the clinics, fidelity scoring on ICDM model activities and examination of patient flow against guidelines. The data collected on clinic characteristics included a facility headcount, caseloads for some (HIV/AIDS, TB, diabetes and hypertension), ICDM model conditions and number of different categories of personnel based on district health information system reports. The monthly patient data (headcounts, caseloads) were collected for a period of 6 months.

To measure fidelity (adherence to ICDM model activities), we first developed fidelity criteria based on the ICDM model manual [7] with a focus on the recommended activities, the recommended reporting tools for the ICDM model and ICRM programme assessment tools. Since no previous studies have assessed the implementation fidelity of the ICDM model, we developed an ICDM model implementation fidelity assessment tool for this study. Our ICDM fidelity assessment tool was designed to measure the extent to which activities under each of the four major components of the ICDM model (facility re-organization, clinical supportive management, assisted self-support and strengthening of support systems) [7] were implemented according to the ICDM model design. Each of the four ICDM model components has various activities that must be implemented to achieve the aims of the ICDM programme [7]. These activities were used to form the basis of the variables to be measured on the implementation fidelity assessment tool. Our fidelity tool was therefore a checklist of variables (activities) under each component. They were scored following similar principles as other chronic diseases management model evaluation studies [43]. As the ICDM model is prescriptive on how activities should be implemented to support integrated care for chronic patients, we posited that failure to implement the recommended activities was regarded as low fidelity.

Each of the four components of the ICDM model comprises four sub-components and each sub-component comprises of four to six activities as outlined in the ICDM model manual (Fig. 1a) [7]. A total of 89 activities or items (facility re-organization 22; clinical supportive management 21 ; assisted self-management 24 , and strengthening of support systems 22) were thus measured in the fidelity assessment tool (Additional file 1). The activities were each scored on a scale, with activity scores ranging from 0 (not implemented at all) to 4 (fully implemented as planned adherent). The activity (item) scores varied depending on the details of the activity. For example, the scores for the activity "pre-dispensing and packing of chronic medication 2-3 days prior to visit" were zero if not implemented, and a maximum score of one if implemented, whereas the score for the activity "building" ranged from 0 (needs major repairs) to 2 (no major repairs needed and floors and walls clean). The total maximum possible fidelity score was 158 per facility (facility re-organization 37; clinical supportive management 39; assisted self-management 39 and strengthening of support systems 43; Fig. 1b).

The ICDM model activities fidelity assessment tool was piloted in four clinics and thereafter revised for clarity and consistency in scoring. Fidelity scoring for the 89 activities was performed through structured observations for such activities like the availability of guidelines and resources, infrastructure maintenance and medicine supply and management. For other items of the ICDM model where observation would be challenging, such as training of healthcare workers, support provided by the DCST and the activities of the WBOT and CHCW in the community were scoring was based on structured questionnaires with healthcare workers. Staff members involved in the implementation of the ICDM model's various components were selected for further data collection using structured questionnaires interviews. The interviews in this study were structured with the aim of assessing how certain activities of the ICDM model that could not be assessed by record review or observations had been performed in the facilities. In addition, all available documents relevant to ICDM model implementation at each facility (human resource and administration files, medicine, and equipment management documents) were reviewed to score the scheduling system and dispensing of medication, among others. Data collection was done over a period of 8 months with multiple visits to the health facilities on different days of the week and times of the month to gather data on a variety of activities. The research team was trained on the protocol and the data collection tools. This team then conducted the pilot and refining of the fidelity assessment tool prior to data collection and fidelity scoring in all the PHC facilities for consistency.

To further examine adherence to the ICDM model guidelines and cross verification of the fidelity scores, we also conducted a patient flow analysis using value stream mapping [44] to ascertain if the processes followed are aligned with the ICDM model guidelines. Patient flow analysis following the value stream mapping was done in four clinics, one with the highest and one with the lowest fidelity scores per district, but with comparable average monthly PHC headcounts. The data collected on the structured observations of patient flow included where and who provided various services for patients with chronic diseases, time for 


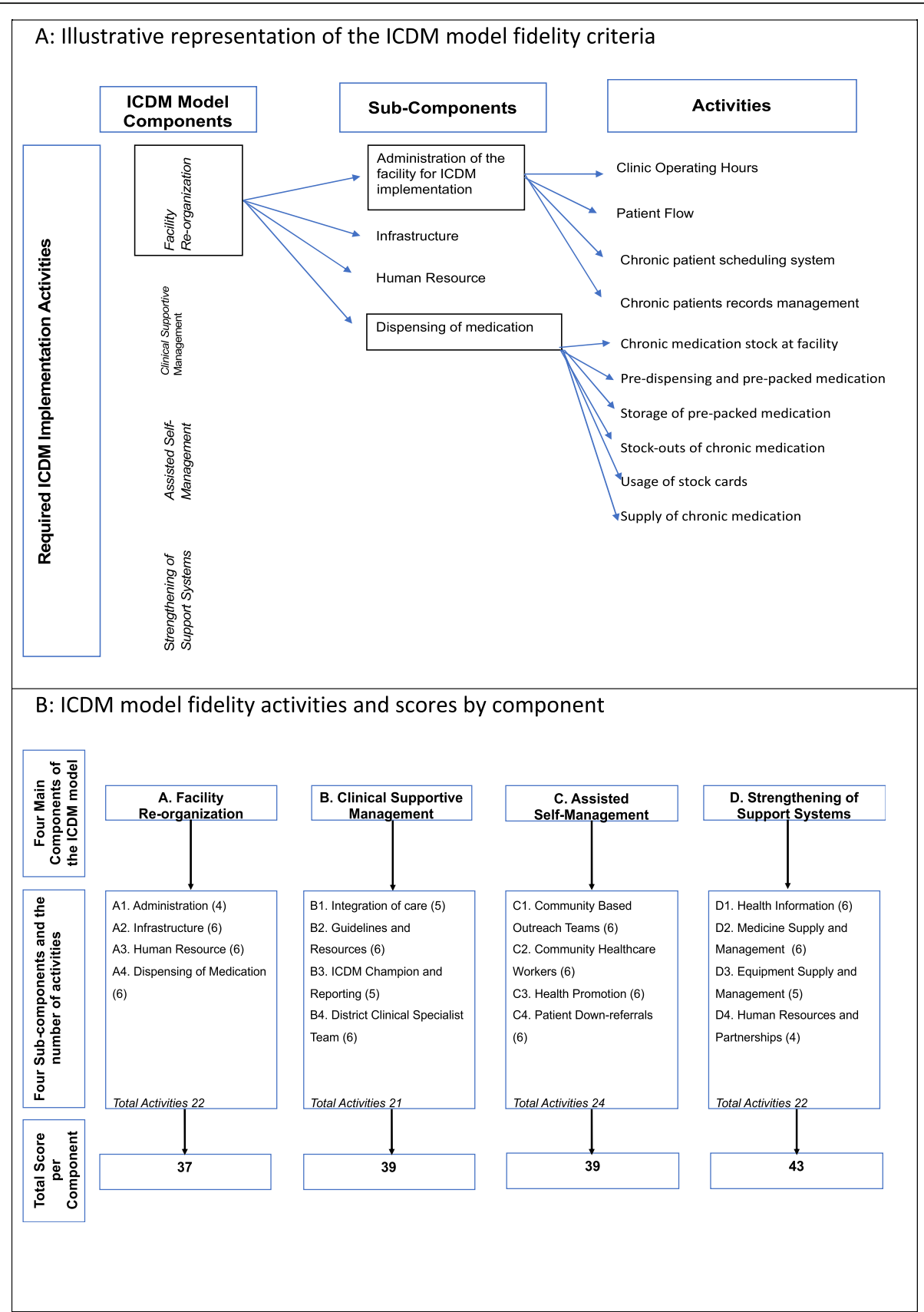

Fig. 1 Illustrative representation of the Integrated Chronic Disease Management Model Fidelity Criteria, and the scores by component. a: Illustrative representation of the ICDM model fidelity criteria. $\mathbf{b}$ : ICDM model fidelity activities and scores by component

the service, the waiting times and areas of inefficiency. An average of 15 patients with a chronic disease per facility were observed from entry into facility till exit.

\section{Data management and analysis}

The data collected on the paper-based ICDM model fidelity assessment tool in the field were captured into a REDCap electronic database [45]. Each facility was allocated a number for study identification and no identifiers were included in the password-protected REDCap database. As part of data cleaning, the data were checked for apparent discrepancies, missing variables and incorrect data. The data were exported into Excel and Statistical Analysis Software (SAS) Enterprise Guide 7.1 for analysis [46].

Descriptive statistics (frequency, median, interquartile ranges, percentages) were used to summarize the data on general clinic characteristics, like personnel, the number of chronic patients, and the services offered. 
Fidelity item scores were summed per component to give four ICDM model component fidelity scores per facility. An overall ICDM model implementation fidelity score was determined per facility by summing the four sub-component scores. The ICDM model implementation fidelity scores were summarized using descriptive statistics (medians and IQR, and converting scores to proportions) and compared across facilities and districts using the Kruskal Wallis and Chi-square tests. In the South African DOH ICRM programme, facilities are scored for ideal clinic status as silver (70-79\%), gold (80-89\%) and platinum (90-100\%), based on assessment on 208 elements, categorized into 10 components covering administration, clinical services provision and health outcomes [17]. A score below $70 \%$ or failure to achieve a minimum percentage in the vital elements is rated as not having achieved ideal clinic status [17]. Although the fidelity assessment of the ICDM model in this study did not encompass all the elements of the ideal clinic, we used similar categories (silver, gold and platinum) in interpreting the fidelity scores because there are no existing norms regarding what constitutes high fidelity of implementation for a chronic care model.

\section{Ethical considerations}

This study was approved by the University of the Witwatersrand (Ref: R14/49) and University of Cape Town's (Ref: 127/2018) Human Research ethics committees. The Gauteng and the North West provincial departments of health also gave their approval.

\section{Results}

\section{Characteristics of the clinics}

All the PHC facilities provided nurse-driven curative and preventative health services and had been implementing the ICDM model since 2011. As shown in Table 1, the 16 PHC facilities that were included in the study sample provided health services to a varied number of patients every month, with a median of 2430 (IQR: 1685-2942) patients aged $>20$ years accessing care per facility per month. However, the PHC monthly headcount varied ranging from an average of 857 to 4946 patients seeking health services. When comparing the two districts, the DKK district had significantly $(p=0.0117)$ more [median 5.5 (IQR: $4.00-9.33$ ) vs 2.0 (IQR: $1.67-2.92)$ ] patients $\geq 5$ years diagnosed with TB monthly. The WR district had significantly more medical officers [3.5 (IQR: 2-4.5) vs 1.0 (IQR: 1.0-1)] and enrolled nurses [3.5 (IQR: 3-5.5) vs 0.0 (IQR: $0.0-1.5$ )] per facility. All facilities had access to at least one medical officer, and each facility had a facility manager. Six facilities did not have a pharmacist assistant.

\section{ICDM model implementation fidelity}

The overall (summation of all component scores) ICDM implementation fidelity score per facility ranged from $68 \%(108 / 158)$ to $86 \%(136 / 158)$. The overall fidelity score was 70 to $79 \%$ (silver status) in six clinics, $\geq 80 \%$ in eight clinics (gold status) and below 70\% (not achieved) in two clinics. The median ICDM implementation fidelity score was 125/158 (IQR: 119-131; 79\%) across both health districts. Strengthening of support

Table 1 Characteristics of the Primary Health Care Clinics by health district

\begin{tabular}{|c|c|c|c|}
\hline Variables & $\begin{array}{l}\text { WR District } \\
\text { Median (IQR) }\end{array}$ & $\begin{array}{l}\text { DKK District } \\
\text { Median (IQR) }\end{array}$ & $P$-Value \\
\hline Primary healthcare headcount per month per facility & $3361(2430-4173)$ & 3690 (2083-3953) & 0.9164 \\
\hline $\begin{array}{l}\text { Primary healthcare headcount of patients }>20 \text { years } \\
\text { old per month per facility }\end{array}$ & $2277(1685-3098)$ & 2626(1584-2942) & 0.8336 \\
\hline Number of HIV/AIDS Adult remaining on ART per facility & $1525(1070-1816)$ & $1572(624-2114)$ & 0.9164 \\
\hline $\begin{array}{l}\text { Number of new Tuberculosis cases ( } \geq 5 \text { years old) } \\
\text { per month per facility }\end{array}$ & $2(1.67-2.92)$ & $5.5(4.00-9.33)$ & 0.0117 \\
\hline $\begin{array}{l}\text { Number of new Diabetic patients ( } \geq 40 \text { years) per } \\
\text { month per facility }\end{array}$ & $8.83(5.08-10.5)$ & $9.67(4.00-13.2)$ & 0.6982 \\
\hline Number of diabetic patients case load per month & $66.3(43.5-89.3)$ & $67.8(36.1-91.4)$ & 0.7527 \\
\hline $\begin{array}{l}\text { Number of hypertensive patients case load (visits) } \\
\text { per month per facility }\end{array}$ & $286(252-395)$ & $252(233-405)$ & 0.4622 \\
\hline Number of Professional Nurses per facility & $7.0(5.5-9.0)$ & $5.5(5.0-11)$ & 0.7105 \\
\hline Number of Enrolled Nurses per facility & $3.5(3.0-5.5)$ & $0.00(0-1.5)$ & 0.0053 \\
\hline Number of Medical Officers per facility & $3.5(2.0-4.5)$ & $1.0(1.00-1)$ & 0.0012 \\
\hline Number of counselors per facility & $3.0(3.0-3)$ & $4.5(2.5-6.5)$ & 0.1685 \\
\hline Ratio of Nurses to PHC monthly headcount per facility & $305(224-358)$ & $408(303-738)$ & 0.1415 \\
\hline Ratio of Medical Officers PHC monthly headcount per facility & $1137(901-1410)$ & $3690(2083-3953)$ & 0.0087 \\
\hline
\end{tabular}


systems and facility re-organization were the highest (silver) scoring ICDM model components with a score of $79 \%$, while assisted self-management score was $78 \%$ and the clinical supportive management was the lowest with 76\%. The Cronbach's alpha (internal consistency of the activities fidelity scoring questions) on clinical supportive management and strengthening of support systems was 0.69 , while for facility re-organization and assisted self-management support it was 0.53 and 0.56 respectively. A calculated score of the Cronbach's alpha that is closer to one indicates a high level of interrelatedness of the items within a scale [47].
The ICDM model's four component activity scores (added and individually) were also compared between clinics and health districts.

\section{Facility re-organization}

The overall score for facility re-organization was silver status $(79 \% ; 462 / 584)$, and the lowest scoring clinic had a score of $65 \%$ (24/37), while the highest clinic score was 92\% (34/37). The median facility re-organization score was 29/37 (IQR: 27-31; 78\%) (Fig. 2). The scheduling of appointments and different streams of care were the least implemented. Nine clinics scored below 75\% (6/8)

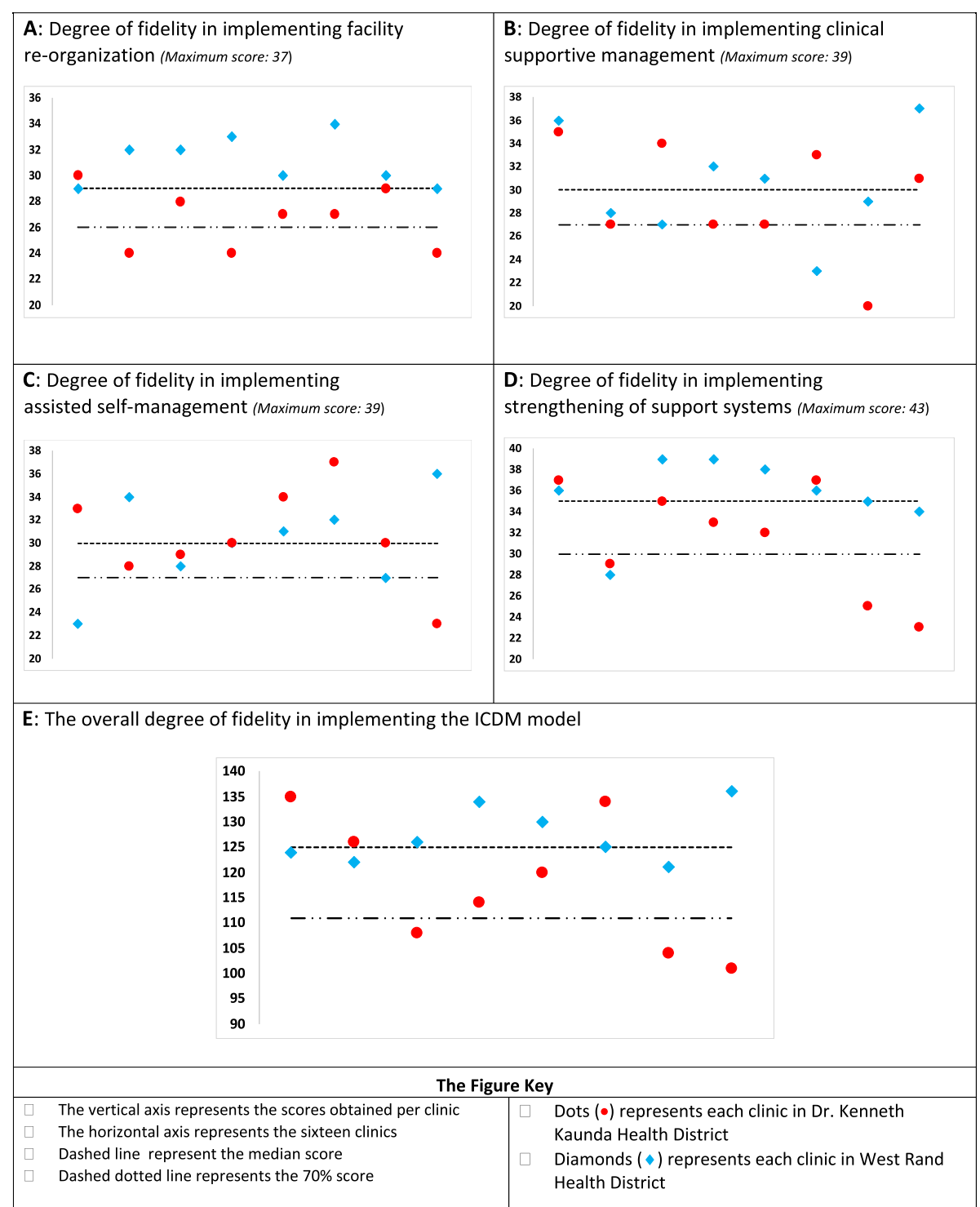

Fig. 2 Graphic representation of the degree of fidelity for the four major components of the ICDM model and overall in the implementation of ICDM model in sixteen clinics. a: Degree of fidelity in implementing facility re-organization (Maximum score: 37 ). b: Degree of fidelity in implementing clinical supportive management (Maximum score: 39). c: Degree of fidelity in implementing assisted self-management (Maximum score: 39). d: Degree of fidelity in implementing strengthening of support systems (Maximum score: 43). e: The overall degree of fidelity in implementing the ICDM model 
on dispensing medication and one clinic could not be assessed as it had pharmacy support from a hospitalbased pharmacy and medication storage and dispensing was not done at the clinic. Half of the clinics obtained scores of $75 \%$ or higher on administrative procedures, infrastructure, personnel training and allocation. Medication is stored in the consulting rooms in most (15/16) of the facilities to improve efficiency according to the ICDM guidelines. However, the medicine supply and management principles (e.g. stock cards, temperature monitoring) were only applied to the medication storage room and not in the consulting rooms where some of the medication is being stored.

\section{Clinical supportive management}

The clinical supportive management overall score across the two districts was silver status $(76 \% ; 477 / 624)$. The lowest score obtained per facility was 51\% (20/39), and the highest score was $95 \%$ (37/39). The median clinical supportive management score was 30/39 (IQR: 27-34; 77\%) (Fig. 2). Only six clinics had the appropriate clinical guidelines available and accessible. Three clinics did not have access to a DSCT. Half of the clinics had a score of $31 / 39(80 \%)$ or more on clinical supportive management (Fig. 2). The scores were high due to the high scores on the activities relating to integration (space, time, healthcare worker, medical records) of care and monitoring and reporting on ICDM implementation. Although all the seven chronic conditions recommended for inclusion into one stream of care, TB services had a separate stream (separate medical records, healthcare worker, and consulting rooms).

\section{Assisted self-management}

The overall score for assisted self-management was also silver status $(78 \% ; 485 / 624)$. The minimum facility score was $59 \%(23 / 39)$ and the maximum facility score was 95\% (37/39). The median assisted self-management score was 30/39 (IQR: 28-34; 77\%). Nine clinics scored $\leq 63 \%$ on health promotion as they did not have regular health promotion talks or chronic diseases' resource material for patients. The score per facility for about two thirds (10/16) of the clinics was above 30/39 (76\%). Almost all (15/16) of the clinics had functional WBOTs and were therefore able to implement down referrals and other pick-up points for chronic medication collection in the community.

\section{Strengthening of support systems}

The overall score for strengthening of support systems across the two districts was silver status $(79 \% ; 536 / 675)$. The lowest score obtained per facility was 53\% (23/43), while the highest score was $91 \%$ (39/43). The median strengthening of support systems score was 35/43 (IQR:
$30-37 ; 81 \%)$. The lowest $(23 / 43 ; 53 \%)$ scoring clinic failed on health information as it did not use the appropriate data collection tools. The least implemented activities were the school health team and equipment supply and management. Ten $(10 / 15 ; 67 \%)$ clinics had a stock visibility system and still used the manual stock cards for medication stock levels monitoring. Most (11/16) of the clinics scored $\geq 75 \%$ (33/43) on strengthening of support systems.

Although the median overall fidelity score for WR was higher than for DKK, the difference was not statistically significant (126, IQR: $123-132$ vs. $117, \mathrm{IQR}: 106-130$; $p=0.1409$ ). The median facility re-organization fidelity score was significantly higher in the WR than in the DKK (31 vs 27/37; $p=0.0030$ ) health district (Fig. 3). There was no significant difference in the supportive management, assisted self-managed and strengthening support systems fidelity scores between the two districts (Fig. 3), even though the WR district median scores for all three of those components were higher than those of the DKK district.

\section{Value stream mapping of patient flow \\ Administration}

There was poor adherence to the ICDM recommendation to have files pre-retrieved the day before for booked patients, except in one clinic. Administrators only retrieved the medical records for patients that have submitted a clinic card or identity document. The administrator would then update the PHC paper-based and electronic registers before patients move to the vital signs station. All the facilities had a separate stream of care for mother-and-child (preventative and promotive) and TB services. However, there was only one stream for chronic and acute care services. In some cases, the next appointment for review was scheduled for 6 months after blood tests, and this could delay issuing of results and taking the necessary clinical actions depending on the received results, like the change of medication, adherence counselling etc. Observed inefficiency was on excess personnel motion as nurses did not have all the required resources in one consultation room and completion of multiple similar documents like a script in the file and for central chronic medicines dispensing and distribution (CCMDD).

\section{Dispensing of medication}

Although the clinics did not pre-pack medication, a 2 months' supply of medication was issued at each visit. Repeat medication collection followed the spaced and fast-line appointment. However, the collection was from the same consulting room or the pharmacy assistant. CCMDD was accessible at three clinics. The allocation of PHC nurses to CCMDD or pharmacy 


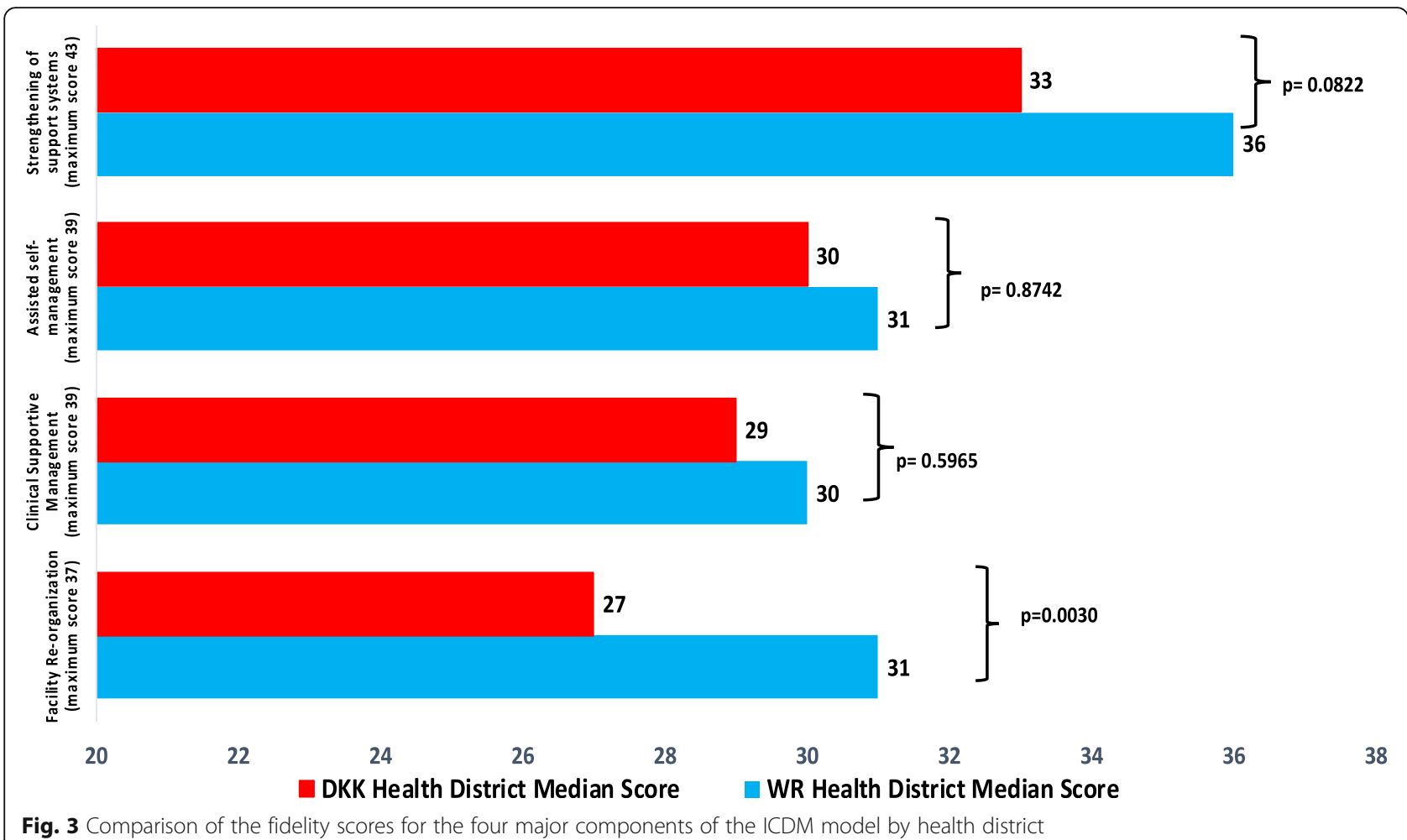

management reduced the number of nurses available to provide primary health care consultations.

\section{Waiting and service times}

On average, patients spent a total of $4 \mathrm{~h} 20 \mathrm{~min}$ (minimum: $2 \mathrm{~h} 33 \mathrm{~min}$. and maximum: $5 \mathrm{~h} 49 \mathrm{~min}$.) at the facility to access health services (Fig. 4). Most (87\%; 3 h; 47 min) of the time was spent waiting for care and 13\% (33 $\min )$ for receiving services. The majority $(70 \% ; 43 / 61)$ of the observed patients spent $3 \mathrm{~h}$ or more at the PHC facility. At the clinic that had the shortest waiting time, patients arrived at different times throughout the day, and the average wait prior to retrieval of medical records was $1 \mathrm{~h} 27 \mathrm{~min}$, compared to $3 \mathrm{~h}$ in the other clinics.

\section{Discussion}

Based on the structured questionnaires, objective observations and facility record reviews, the implementation fidelity of the ICDM model was $79 \%$ in the two health districts, with some variability between PHC facilities. Fourteen PHC clinics had a an ICDM implementation fidelity score of $\geq 70 \%$ on implementation of the ICDM model. The clinics in the WR health district had higher fidelity scores compared to those in DKK for all four ICDM components, but the differences were not statistically significant except for the for the facility re-organization component. Scheduling of appointments, pre-retrieval of medical records, different streams of care, and equipment supply and management were the least implemented ICDM model activities. In addition, access to clinical guidelines and support by the DCST was inadequate at some of the clinics. There were high fidelity scores on integration of care, infrastructure, functional WBOTS and medicine supply and management. Waiting time for services was over $3 \mathrm{~h}$, mostly at the medical records retrieval station. Observed unintended consequences of implementing the ICDM model guidelines included reduced personnel for patient care when nurses are allocated to CCMDD or pharmacy, and medication management in consulting rooms. The findings from this study give valuable information on the level of fidelity in the implementation of the ICDM model at a time that the South African DOH is focusing on primary healthcare revitalization in preparation for the national health insurance [14-16].

Although the scoring for the ICDM model fidelity scoring did not contain all the components included in the ICRM programme, applying the ICRM scale [silver (70-79\%), gold (80-89\%) and platinum $(90-100 \%)]$ to our study would imply that $12.5 \%(2 / 16)$ clinics in this study did not achieve ideal clinic status on chronic disease health services. Silver status $(70-79 \%)$ was obtained by $37.5 \%(6 / 16)$ of the assessed clinics, while $50 \%(8 / 16)$ achieved gold status ( $80-89 \%$ on chronic services). No clinic score fell into the platinum category in this study. The higher number of clinics scoring silver and gold status compared to not achieved ideal clinic status (12.5\% 


\section{A: ICDM model recommended patient flow}

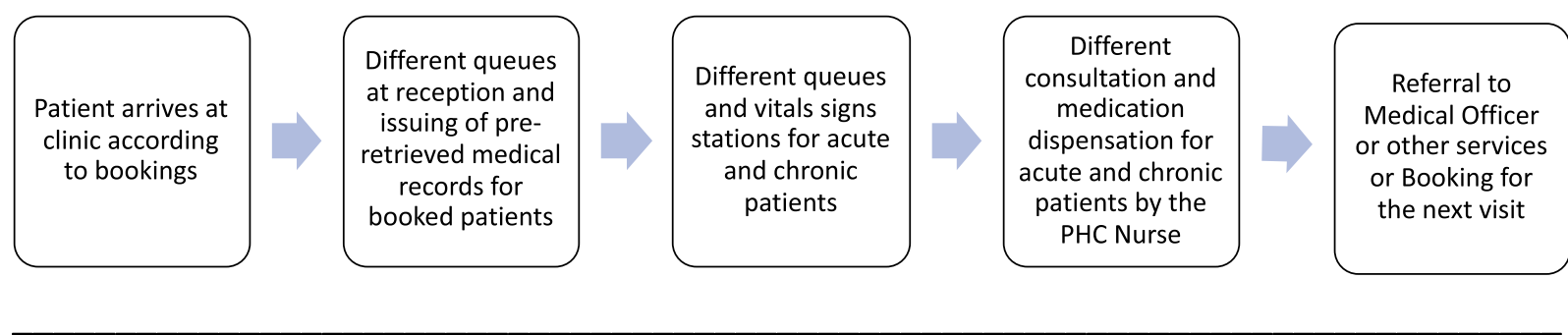

\section{B: Value stream mapping of patient flow in four clinics}
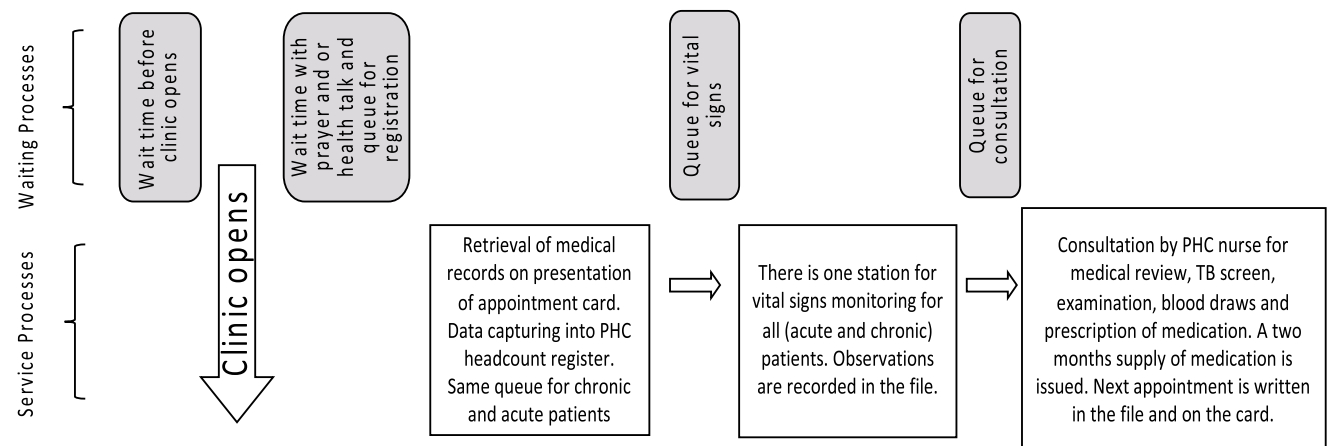

Booking/

Home/

Medical Officer
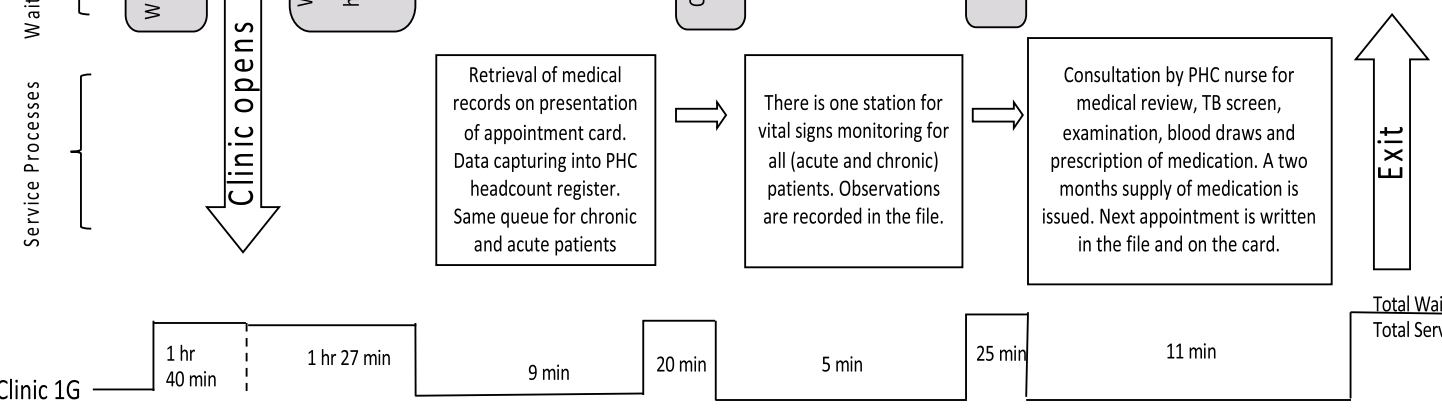

Total Wait time $=3$ hrs $52 \mathrm{~min}$ Total Service Time $=24 \mathrm{~min}$

Clinic 1 40 min

Clinic $1 \mathrm{H} \longrightarrow 35 \mathrm{~min}$

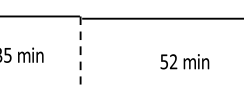

$16 \min$
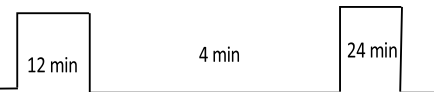

$10 \mathrm{~min}$

Total Wait time $=2 \mathrm{hrs} 3 \mathrm{~min}$ Total Service Time $=30 \mathrm{~min}$

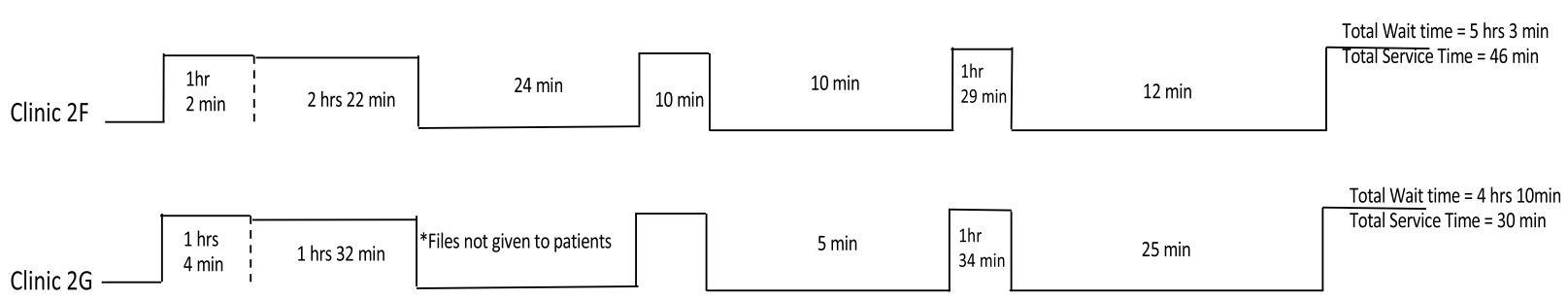

\footnotetext{
* The administrators in clinic $2 \mathrm{G}$ takes the files straight to the vital station and the patient remains in the same waiting area and chairs until they are called for vital signs observations.
}

Fig. 4 ICDM model recommended patient flow and value stream mapping of patient flow in four clinics. a: ICDM model recommended patient flow. $\mathbf{b}$ : Value stream mapping of patient flow in four clinics

vs $87.5 \%)$ could be indicative of broad improvements in clinic functioning (infrastructure, personnel and supply chain management) under the ICRM programme [17]. In a peer-peer review conducted in 2016 under the ICRM scale-up process, the number of clinics scoring over $70 \%$ (achieved ideal clinic status) was noted to have increased from 139 in 2013 to 445 [17]. No previous studies on ICDM model fidelity are available. However, studies that have looked at implementation of other chronic diseases management models, highlighted a high variability in the combination of components included the chronic disease models and the ways in which they are implemented $[43,48]$. In our study, the overall level of implementing the chronic care model 
elements according to guidelines varied between 55 and $89 \%$ [48-50]. The highest (89\%) level of fidelity observed was in a continuum of care programme, with 16 of the 18 components implemented according to the guidelines [48].

In our study, there was variability between health facilities on the level of fidelity in the implementation of the ICDM model, with facility re-organization component having a significantly higher level of fidelity in WR, compared to the DKK health district. In studies on the integration of services for various chronic diseases in primary healthcare practices, there was also high level of variability in the level of implementation on each of the components $[49,50]$. Although the primary healthcare monthly headcount of patients was slightly higher in the participating clinics of the DKK district, the district had fewer medical officers and nurses. The lower human resource (clinical personnel) level could have contributed to the lower fidelity in the implementation of the ICDM model in the DKK health district compared to the WR. Other contextual factors that have been described as facilitators for successful implementation and sustainability of chronic care models and were not assessed in this study, include the commitment and support of the leadership, training of personnel, participants responsiveness, sufficient funding, acceptability of the intervention and collaboration with other sectors $[43,48,51-53]$. The observed variability in fidelity level across ICDM model components and health districts could indicate adaptations to the model to fit different contexts. The availability of infrastructure and resources, the capacity of the implementing teams and time constraints are some of the factors that could lead to spontaneous adaptations of an intervention to enhance its suitability to context $[29,30]$. Low fidelity in the implementation, especially if the core components have been removed, could affect the effectiveness of the intervention [30]. The impact of contextual factors on the variability in the implementation fidelity of the various activities of the ICDM model in the two health districts and how this variability affects ICDM programme effectiveness needs further research. In addition, that data would inform the implementation of the ICDM model in other health systems or populations (scaling-out).

The ICDM model activities that had low $(<70 \%)$ fidelity in our study included administration (pre-retrieval of medical records and different streams of care), health promotion and clinical supportive management by the DCST. Improvements in clinical outcomes and operations have been documented in chronic care models that provide decision support and delivery system design [43]. Lack of clinical leadership could adversely affect the expected outcomes and sustainability of the ICDM model $[32,38]$. Redesign of service delivery, integration of services and decision support were also inadequately implemented in other chronic care models evaluations, with scores of $39-46 \%$; 46 and $58 \%$ respectively [49, 50]. Clinical management decision support should be enhanced in this setting where nurses' knowledge on chronic diseases is inadequate and guidelines are not readily available [54-57]. Although there was a high level of integration (time, healthcare provider, space) TB patients had a separate stream from patients with other chronic conditions, despite the recommendations by $\mathrm{WHO}$ and UNAIDS to integrate TB and HIV services [58, 59].

A high level of fidelity was discovered on integration of services and the facilitated self-management and community support with WBOTs and CHCW. Assisted self-management support was also the most prominent component of several chronic care models and resulted in improvements in health outcomes [43], and in an evaluation of other primary healthcare practices on the level of implementation on the chronic care model components, self-management support scored 48\% [50]. Contextual adaptations (modifying the adaptable while maintaining key components of interventions) may be needed to enhance feasibility, reach, and acceptability $[19,20,29,30]$. The ICDM model guidelines do not, but should clearly outline which are the adaptable and which key components of the model to optimise implementation fidelity, and facilitate scale-out, scale-up and process evaluations.

Regarding waiting times, 3 hours is the maximum time patients are expected to spend in a health facility when accessing services, based on the ideal clinic standards in South Africa [18]. In this study, $70 \%$ of observed patients were at the PHC facilities for $3 \mathrm{~h}$ or more. The high median waiting time in our study was similar to the findings of Egbujie et al., which showed that some clinics in South Africa have reduced while others have increased waiting time after the implementation of the ICRM programme [60]. Observed inefficiencies in our study included excessive waiting time and nurses' motion and rework. There were also unintended consequences like poor adherence to guidelines on medication management in consulting rooms and redundancy of clinical staff when allocated to non-clinical ICDM model activities. The ICDM model and ICRM programme also follow the lean thinking principles on waste reduction like waiting time, excess inventory, underutilized staff and excess people motion $[7,18]$. Our study found that the participating PHC facilities did not perform well on waste reduction according to these lean principles .

\section{Strengths and limitations}

This study has a number of strengths. Firstly, multiple visits to health facilities over 8 months to observe the level of fidelity in the implementation of the ICDM model allowed us to assess clinics when they had different patient and personnel numbers. Secondly, the use of implementation research principles implies that this 
research ensures evidence-based decisions on ICDM model implementation improvements and on how the lesson learned could affect scale-up and scale -out and policies. Thirdly, application of patient flow analysis identified specific areas of inefficiencies in the delivery of chronic health services stream.

Limitations of this study included that the weighting of the scores of the fidelity criteria was based on the number of activities required, and not on how critical that activity was in achieving the ICDM model objectives. Some of the items on the fidelity criteria were scored based on the data provided in the structured questionnaire by the implementing healthcare workers, and this could have introduced social desirability bias. Assessments focused significantly on the presence of systems and processes that have been recommended, and not the quality of the implementation of the components.

\section{Conclusion}

There was a high level of fidelity of implementation of the ICDM model in the two health districts, with some variability across ICDM model scores on components and PHC facilities. The highest median scores were on the ICDM model components of facility re-organization and strengthening of support systems. Relentless and continuous monitoring and evaluation of the PHC clinics on the ICRM programme and integrated clinical services is essential to ensure that these gains are not lost. Increased focus on quality in the implementation of elements that had high levels of fidelity like facility reorganization, assisted self-management and facilitated community support could further enhance efficiencies. The ICDM model items that were described as having lower degrees of fidelity (different streams of care, administration and health promotions) indicate opportunities for improvement of the current implementation of the ICDM model and how to support normalization into routine practice of the model. More research is needed to identify the determinants of ICDM model implementation fidelity and on innovative adaptations that can improve models' processes and its implementation at local level without affecting the intended model's outcomes.

\section{Supplementary information}

Supplementary information accompanies this paper at https://doi.org/10. 1186/s12913-019-4785-7.

Additional file 1. Implementation Fidelity of the Integrated Chronic Disease Management Model - Assessment Tool Activities.

\section{Abbreviations}

CCMDD: Centralized chronic medication dispensing and distribution; DOH: Department of Health; HIV: Human Immune Deficiency Syndrome; HPT: Hypertension; ICDM: Integrated chronic disease management; ICRM: Ideal clinic realisation and maintenance programme; ICSM: Integrated clinical services management; MRC: Medical Research Council; PHC: Primary healthcare; TB: Tuberculosis; WHO: World Health Organization

\section{Acknowledgements}

We would like to acknowledge the personnel and patients at the 16 facilities who allowed us to observe them while working and who answered questions on the functioning of the clinics.

\section{Authors' contributions}

$\mathrm{LL}$ was involved in the conception, study design, data collection, data cleaning and analysis and writing of the manuscript. OAA, MK and TO contributed to the conception, study design and critical review of the manuscript.

AR and PP were involved in data collection, data cleaning and review of the manuscript. $\mathrm{KH}$ was involved in the data cleaning and analysis, and review of the manuscript.All authors read and approved the final manuscript.

\section{Funding}

South African Medical Research Council (SA MRC) Self-Initiated Research Grant (ID:494184). The views and opinions expressed are those of the author(s) and do not necessarily represent the official views of the SA MRC.

The sponsor had no role in data collection, analysis or reporting of results.

\section{Availability of data and materials}

The data on the implementation fidelity of the ICDM model is available on

Figshare, via the following URL: https://doi.org/10.6084/m9.figshare.9339029.v1

\section{Ethics approval and consent to participate}

The protocol was approved by the University of Cape Town and University of the Witwatersrand's Human Research ethics committees.

Consent for publication

Not Applicable

\section{Competing interests}

The authors declare that they have no competing interests.

\section{Author details}

${ }^{1}$ Perinatal HIV Research Unit (PHRU), SA MRC Soweto Matlosana Collaborating Centre for HIV/AIDS and TB, Faculty of Health Sciences, University of the Witwatersrand, Johannesburg, South Africa. ${ }^{2}$ Division of Public Health Medicine, School of Public Health and Family Medicine, University of Cape Town, Cape Town, South Africa. ${ }^{3}$ Health Economics Unit, School of Public Health and Family Medicine, University of Cape Town, Cape Town, South Africa. ${ }^{4} \mathrm{MRC}$ Epidemiology Unit, University of Cambridge, Cambridge, UK. ${ }^{5}$ Department of Community Health, School of Public Health, Faculty of Health Sciences, University of the Witwatersrand, Johannesburg, South Africa.

Received: 7 August 2019 Accepted: 26 November 2019

Published online: 16 December 2019

\section{References}

1. WHO and UNICEF. Declaration of Astana. Global Conference on Primary Health Care, Astana, Kazakhstan: World Health Organization and the United Nations Children's Fund; 2018.

2. World Health Organization. Innovative care for chronic conditions: Building Blocks for Action; 2013. Available from: http://www.who.int/chp/knowledge/ publications/icccreport/en/.

3. Aantjes CJ, Quinlan TKC, Bunders JFG, Durban SA. Chronic care in Africa How the experience with expanding antiretroviral treatment programmes for HIV can serve patients with other chronic conditions. Durban: South African AIDS Conference; July 2016; 2016.

4. Ramthol SS. Impact of NIMART and centralized chronic medication dispensing and distribution in decongesting health facilities. 21 st ed. Durban: International AIDS Conference; 2016.

5. Venables E, Edwards J, Baert S, Etienne W, Ritter H, Khabala K, et al. Integrating HIV and NCD patients in adherence clubs in Kibera, Kenya: A qualitative study. 21st ed. Durban: International AIDS conference; 2016.

6. Coventry $P$, Lovell K, Dickens C, Bower P, Chew-Graham C, McElvenny D, et al. Integrated primary care for patients with mental and physical 
multimorbidity: Cluster randomised controlled trial of collaborative care for patients with depression comorbid with diabetes or cardiovascular disease. BMJ. 2015;16(350):638.

7. National Department of Health of South Africa. Integrated chronic disease management manual. South Africa: A step-by-step guide for implementation; 2012.

8. Kim DJ, Westfall AO, Chamot E. Multimorbidity patterns in HIV-infected patients: the role of obesity in chronic disease clustering. Immune Defic Syndr. 2012;61(5):600-5. https://doi.org/10.1097/QAl.0b013e31827303d5.

9. Mayosi BM, Flisher AJ, Lalloo UG, Sitas F, Tollman SM, Bradshaw D. The burden of non-communicable diseases in South Africa. Lancet. 2009; 374(9693):934-47. https://doi.org/10.1016/s0140-6736(09)61087-4 PubMed PMID: 19709736Epub 2009/08/28.

10. Statistics South Africa. Mortality and causes of death in South Africa: Findings from death notification Statistics South Africa, Pretoria, South Africa: 2014

11. Steyn K, Damasceno A. Lifestyle and related risk factors for chronic diseases. In: Jamison DT FR, Makgoba MW, et al., editor. Disease and mortality in SubSaharan Africa Second ed. Washington DC: The World Bank: 2006.

12. Nuño R, Coleman $K$, Bengoa R, Sauto R. Integrated care for chronic conditions: the contribution of the ICCC framework. Health Policy. 2012; 105(1):55-64. https://doi.org/10.1016/j.healthpol.2011.10.006

13. Mahomed $\mathrm{OH}$, Asmall SJ. Development and implementation of an integrated chronic disease model in South Africa: Lessons in the management of change through improving the quality of clinical practice. Int J Integr Care. 2015;15:e308.

14. Keeton C. Bridging the gap in South Africa. Bull World Health Organ. 2010; 88:803-4.

15. Bateman C. How will NHI affect my practice? Workshop seeks answers. S Afr Med J. 2010;100(6):350-2

16. Gray A, Vawda Y, Padarath A, King J, English R. Health policy and legislation. In: Padarath a, King J, R E, editors. South African health review. Durban: Health Systems Trust; 2015.

17. Hunter JRCT, Asmall S, Tucker JM, Ravhengani NM, Mokgalagadi Y. The ideal clinic in South Africa: progress and challenges in implementation. In: Padarath A, Barron P, editors. South Africa health review. Durban: South Africa; 2017.

18. Department of Health. Integrated clinical services management manual. Republic of South Africa: 2016.

19. Aarons GA, Sklar M, Mustanski B, Benbow N, Brown CH. "Scaling-out" evidence-based interventions to new populations or new health care delivery systems. Implement Sci : IS. 2017;12(1):111-. doi: https://doi.org/10. 1186/s13012-017-0640-6. PubMed PMID: 28877746.

20. Anyon Y, Roscoe J, Bender K, Kennedy H, Dechants J, Begun S, et al. Reconciling adaptation and fidelity: implications for scaling up high quality youth programs. J Prim Prev. 2019;40(1):35-49. https://doi.org/10.1007/ s10935-019-00535-6 PubMed PMID: 30659405, Epub 2019/01/20.

21. Ameh S, Klipstein-Grobusch K, D'Ambruoso L, Kahn K, Tollman SM, GómezOlivé X. Effectiveness of an integrated chronic disease management model in improving patients' CD4 count and blood pressure in a rural South African setting: a controlled interrupted time series analysis. 21 st ed. Durban: International AIDS Conference; 2016.

22. Mahomed $\mathrm{OH}$, Naidoo S, Asmall S, Taylor M. Improving the quality of nurse clinical documentation for chronic patients at primary care clinics: A multifaceted intervention. Curationis. 2015;38(1).

23. Ameh S, Klipstein-Grobusch K, D'Ambruoso L, Kahn K, Tollman SM, Gómez-Olivé X. Quality of integrated chronic disease care in rural South Africa: User and provider perspective. 21st ed. Durban: International AIDS Conference; 2016

24. World Health Organization. A guide to implementation research in the prevention and control of noncommunicable diseases. Geneva: WHO; 2016

25. David H, Peters NT, Tran TA. Implementation research in health: a practical guide. Alliance for Health Policy and Systems: World Health Organization; 2013.

26. Proctor $E$, Silmere $H$, Raghavan $R$, Hovmand $P$, Aarons $G$, Bunger $A$, et al. Outcomes for implementation research: conceptual distinctions, measurement challenges, and research agenda. Admin Pol Ment Health. 2011;38(2):65-76. https://doi.org/10.1007/s10488-010-0319-7.

27. Mowbray CT, Holter MC, Teague GB, Bybee D. Fidelity criteria: development, measurement, and validation. Am J Eval. 2003;24:315-40.
28. Carroll C, Patterson M, Wood S, Booth A, Rick J, Balain S. A conceptual framework for implementation fidelity. Implement Sci. 2007;2(40):40.

29. Carvalho ML, Honeycutt S, Escoffery C, Glanz K, Sabbs D, Kegler MC. Balancing fidelity and adaptation: implementing evidence-based chronic disease prevention programs. J Public Health Manag Pract. 2013;19(4):34856. https://doi.org/10.1097/PHH.0b013e31826d80eb PubMed PMID: 23462111, Epub 2013/03/07.

30. Escoffery C, Lebow-Skelley E, Haardoerfer R, Boing E, Udelson H, Wood R, et al. A systematic review of adaptations of evidence-based public health interventions globally. Implement Sci. 2018;13(1):125. https://doi.org/10. 1186/s13012-018-0815-9 PubMed PMID: 30257683; PubMed Central PMCID: PMCPMC6158804, Epub 2018/09/28.

31. Eboreime EA, Abimbola S, Obi FA, Ebirim O, Olubajo O, Eyles J, et al. Evaluating the sub-national fidelity of national Initiatives in decentralized health systems: Integrated Primary Health Care Governance in Nigeria. BMC Health Serv Res. 2017;17(1):227. https://doi.org/10.1186/s12913-017-2179-2. PubMed PMID: 28327123; PubMed Central PMCID: PMCPMC5361827, Epub 2017/03/23

32. Mahomed $\mathrm{OH}$, Asmall $\mathrm{S}$, Voce $\mathrm{A}$. Sustainability of the integrated chronic disease management model at primary care clinics in South Africa. Afr J Prim Health Care Fam Med. 2016;8(1):e1-7. https://doi.org/10.4102/phcfm. v8i1.1248 PubMed PMID: 28155314.

33. Lebina L, Alaba O, Kawonga M, Oni T. Process evaluation of fidelity and costs of implementing the integrated chronic disease management model in South Africa: mixed methods study protocol. BMJ Open. 2019;9(6): e029277. https://doi.org/10.1136/bmjopen-2019-029277.

34. UNAIDS. HIV and AIDS estimates 2017.

35. Statistics South Africa. Use of health facilities and levels of selected health conditions in South Africa: Findings from the General Household Survey. 2011 Report No. 03-00-05.

36. Africa SS. General household survey; 2016.

37. Nxumalo N, Goudge J, Manderson L. Community health workers, recipients' experiences and constraints to care in South Africa - a pathway to trust. AIDS Care. 2016;28(Suppl 4):61-71. https://doi.org/10.1080/09540121.2016. 1195484 PubMed PMID: 27345712, Epub 2016/06/28

38. Ministerial Task Team. District clinical specialist teams in South Africa. South Africa: National Department of Health; 2012.

39. Massyn N, Peer N, Padarath A, Barron P, Day C. District health barometer 2014/15. Durban: Health Systems Trust; 2015.

40. Day C, Gray A. Health and related indicators. Health Systems Trust: South Africa; 2016

41. Shisana $O, D L$, Rehle $T$, Simbayi L, Zuma K, Dhansay A, Reddy P, Parker W, Hoosain E, Naidoo P, Hongoro C, Mchiza Z, Steyn NP, Dwane N, Makoae M, Maluleke T, Ramlagan S, Zungu N, Evans MG, Jacobs L, Faber M. SANHANES-1. In: The South African National Health and Nutrition Examination Survey, 2012: SANHANES-1: the health and nutritional status of the nation; 2014.

42. Shisana O, Rehle T, Simbayi LC, Zuma K, Jooste S, Zungu N, et al. South African national HIV prevalence, incidence and behaviour survey, 2012. South Africa: Department of Health; 2012.

43. Davy C, Bleasel J, Liu H, Tchan M, Ponniah S, Brown A. Effectiveness of chronic care models: opportunities for improving healthcare practice and health outcomes: a systematic review. BMC Health Serv Res. 2015;15:194. https://doi.org/10.1186/s12913-015-0854-8 PubMed PMID: 25958128.

44. Markovitz D. Value stream mapping reference pack, 201430 2019. Available from: https://static1.squarespace.com/static/5553cc0ae4b00483b179bda2/ t/556344e2e4b08f92bdb9a651/1432569058017/NSM+Guide.pdf.

45. REDCap Technical Review [Internet]. 2014.

46. SAS Institute Inc. SAS ${ }^{\circledR}$ Tasks in SAS ${ }^{\circledR}$ Enterprise Guide ${ }^{\oplus}$ 7.1. Cary, NC: SAS Institute Inc.; 2018

47. Tavakol M, Dennick R. Making sense of Cronbach's alpha. Int J Med Educ. 2011;2:53-5. https://doi.org/10.5116/ijme.4dfb.8dfd PubMed PMID: 28029643.

48. Hasson H, Blomberg S, Duner A. Fidelity and moderating factors in complex interventions: a case study of a continuum of care program for frail elderly people in health and social care. Implement Sci. 2012;7:23. https://doi.org/ 10.1186/1748-5908-7-23 PubMed PMID: 22436121; PubMed Central PMCID: PMCPMC3342887. Epub 2012/03/23.

49. Wong K, Boulanger L, Smalarz A, Wu N, Fraser K, Wogen J. Impact of care management processes and integration of care on blood pressure control in diabetes. BMC Fam Pract. 2013;14:30. https://doi.org/10.1186/1471-2296- 
14-30 PubMed PMID: 23445773; PubMed Central PMCID: PMCPMC3599005. Epub 2013/03/01.

50. Solberg LI, Asche SE, Shortell SM, Gillies RR, Taylor N, Pawlson LG, et al. Is integration in large medical groups associated with quality? Am J Manag Care. 2009;15(6):e34-41 Epub 2009/06/12. PubMed PMID: 19514807.

51. Harrison Ml, Paez K, Carman KL, Stephens J, Smeeding L, Devers KJ, et al. Effects of organizational context on Lean implementation in five hospital systems. Health Care Manag Rev. 2016;41 (2):127-44. https://doi.org/10.1097/ hmr.0000000000000049 PubMed PMID: 00004010-201604000-00005.

52. Goodridge D, Rana M, Harrison EL, Rotter T, Dobson R, Groot G, et al. Assessing the implementation processes of a large-scale, multi-year quality improvement initiative: survey of health care providers. BMC Health Serv Res. 2018;18(1):237. https://doi.org/10.1186/s12913-018-3045-6 PubMed PMID: 29615014

53. Hung D, Gray C, Martinez M, Schmittdiel J, Harrison MI. Acceptance of Lean redesigns in primary care: A contextual analysis. Health Care Manag Rev. 2016. https://doi.org/10.1097/hmr.0000000000000106 PubMed PMID: 2693 9032. Epub 2016/03/05.

54. Maimela E, Geertruyden JP, Alberts M, Modjadji SE, Meulemans H, Fraeyman $J$, et al. The perceptions and perspectives of patients and health care providers on chronic diseases management in rural South Africa: a qualitative studyBMC Health Serv Res. 2015;15:143. Epub 8 April 2015.

55. Siko PR, van Deventer C. Compliance with standard treatment guidelines in the management of hypertension: a review of practice of healthcare workers in Potchefstroom, north West Province, South Africa. S Afr Fam Pract. 2017:59(2):72-7. https://doi.org/10.1080/20786190.2016.1272246.

56. Adedeji AR, Tumbo J, Govender I. Adherence of doctors to a clinical guideline for hypertension in Bojanala district, north-West Province, South Africa. Afr J Prim Health Care Fam Med. 2015;7(1):776. https://doi.org/10. 4102/phcfm.v7i1.776 PubMed PMID: 26245596.

57. Dube FN, Uys LR. Primary health care nurses' management practices of common mental health conditions in KwaZulu-Natal, South Africa. 2015; 2015:38(1). Epub 2015-02-27. https://doi.org/10.4102/curationis.v38i1.1168.

58. World Health Organization. WHO policy on TB infection control in healthcare facilities, congregate settings and households. Geneva: WHO; 2009.

59. UNAIDS. The need to scale up integrated TB/HIV care. 201808 June 2019. Available from: https://www.unaids.org/en/resources/presscentre/ featurestories/2018/september/20180926_UNGA_TBHIV.

60. Egbujie BA, Grimwood A, Mothibi-Wabafor EC, Fatti G, Tshabalala A, Allie S, et al. Impact of 'Ideal Clinic' implementation on patient waiting time in primary healthcare clinics in KwaZulu-Natal Province, South Africa: a beforeand-after evaluation. South African medical journal =. Suid-Afrikaanse tydskrif vir geneeskunde. 2018;108(4):311-8. https://doi.org/10.7196/SAMJ. 2017.v108i4.12583 PubMed PMID: 29629682. Epub 2018/04/10.

\section{Publisher's Note}

Springer Nature remains neutral with regard to jurisdictional claims in published maps and institutional affiliations.

Ready to submit your research? Choose BMC and benefit from:

- fast, convenient online submission

- thorough peer review by experienced researchers in your field

- rapid publication on acceptance

- support for research data, including large and complex data types

- gold Open Access which fosters wider collaboration and increased citations

- maximum visibility for your research: over $100 \mathrm{M}$ website views per year

At BMC, research is always in progress.

Learn more biomedcentral.com/submissions 